\title{
VARIABILIDADE DA PRODUTIVIDADE DA SOJA EM FUNÇÃO DE ATRIBUTOS FÍSICOS DE UM LATOSSOLO VERMELHO DISTROFÉRRICO SOB PLANTIO DIRETO(1)
}

\author{
Gilberto Rosa Filho( ${ }^{(2)}$, Morel de Passos e Carvalho( ${ }^{(3)}$, Marcelo Andreotti ${ }^{(4)}$, Rafael \\ Montanari $^{(5)}$, Flávio Ferreira da Silva Binotti ${ }^{(5)} \&$ Máila Terra Gioia ${ }^{(2)}$
}

\begin{abstract}
RESUMO
Atualmente, no cenário nacional, a cultura da soja em plantio direto é muito utilizada na integração agricultura-pecuária. No ano agrícola de 2006/2007, no município de Selvíria (MS), entre as latitudes de $20^{\circ} 18$ ' 05 " $\mathrm{S}$ e $20^{\circ} 18$ ' 28 " S e as longitudes de $52^{\circ} 39$ ' 02 " W e $52^{\circ} 40$ ' 28 " $\mathrm{W}$, foi analisada a produtividade da soja, em plantio direto, em função de alguns atributos físicos de um Latossolo Vermelho distroférrico. $O$ objetivo foi selecionar, entre os atributos do solo pesquisados, aquele que melhor se apresentasse para explicar a variabilidade espacial da produtividade agrícola. Para isso, foi instalada a malha geoestatística para a coleta dos dados do solo e da planta, contendo 120 pontos amostrais, numa área de $4.068 \mathrm{~m}^{2}$ e declive homogêneo de $0,025 \mathrm{~m} \mathrm{~m}^{-1}$. Do ponto de vista linear e espacial, a elevada produtividade de grãos de soja pôde ser explicada em função da densidade do solo e da umidade volumétrica. A baixa variabilidade da maioria dos atributos do solo indicou que o plantio direto é um sistema que proporciona a homogeneização do ambiente físico do solo.
\end{abstract}

Termos de indexação: integração agricultura-pecuária, manejo do solo, qualidade

física do solo, agricultura de precisão, krigagem, Glycine max.

\footnotetext{
(1) Parte da Dissertação de Mestrado do primeiro autor do Programa de Pós-Graduação em Sistemas de Produção - Faculdade de Engenharia - UNESP/Campus de Ilha Solteira. Bolsista FAPESP. Recebido para publicação em maio de 2008 e aprovado em fevereiro de 2009.

(2) Mestrando da Faculdade de Engenharia - UNESP/Campus de Ilha Solteira. Caixa Postal 31, CEP 15385000 Ilha Solteira (SP). E-mails: gilberto.agro@yahoo.com.br; mailaterra@gmail.com

${ }^{(3)}$ Professor Adjunto do Departamento de Fitossanidade, Engenharia Rural e Solo - Faculdade de Engenharia, UNESP. E-mail: morel@agr.feis.unesp.br

(4) Professor Assistente Doutor da Faculdade de Engenharia - UNESP. E-mail: dreotti@agr.feis.unesp.br

${ }^{(5)}$ Doutorando da Faculdade de Engenharia, UNESP. E-mails: rafamontana@hotmail.com; flavio_agro@hotmail.com
} 


\title{
SUMMARY: SOYBEAN YIELD VARIABILLITY REGARDING PHYSICAL PROPERTIES OF A TYPIC ACRUSTOX UNDER NO-TILLAGE
}

\begin{abstract}
Nowadays no-tillage soybean is widely used in crop-livestock farming systems in Brazil. The yield of no-tillage soybean was analysed in the county of Selviria (latitudes from $20^{\circ} 18^{\prime} 05$ " $S$ and $20^{\circ} 18^{\prime} 28^{\prime \prime} S$ and the longitudes de $52^{\circ} 39^{\prime} 02$ " $W$ and $52^{\circ} 40^{\prime} 28^{\prime \prime} \mathrm{W}$ (Mato Grosso do Sul State - Brazil), in the 2006/07 growing season, as affected by some physical properties of a local Typic Acrustox. The objective was to determine the soil property that could best explain the variability in the agricultural productivity. For this purpose, a geostatistical grid with 120 sampling points was installed to collect soil and plant data in an area of 4,068 $\mathrm{m}^{2}$, on a homogeneous slope of $0.025 \mathrm{~m} \mathrm{~m}^{-1}$. From the linear and spatial point of view, the high soybean grain yield could be explained by bulk density and volumetric moisture. The low variability of most soil properties indicated no-tillage as a system that induces homogenization of the soil physical environment.
\end{abstract}

Index terms: crop-livestock integration, soil management, soil physical quality, precision farming, kriging, Glycine max.

\section{INTRODUÇÃO}

Na safra de 2006/2007, o Brasil figurou como o segundo produtor mundial de soja, com uma área de $20,7 \cdot 10^{6}$ ha, equivalente à produção de $58,4 \cdot 10^{6}$ t. A produção da soja corresponde a 94,5 \% das oleaginosas cultivadas no país, constituindo-se numa das mais tecnificadas culturas, e no principal produto agrícola de exportação. Nos últimos anos, houve um aumento considerável da sua área cultivada, devido à abertura de novas fronteiras agrícolas, como é o caso do Cerrado e da Amazônia. A sua crescente utilização na recuperação do solo degradado, por meio do seu emprego na rotação de culturas com a pastagem, atualmente designado como integração agriculturapecuária, é uma excelente alternativa para o uso agrícola, sobretudo por explorar o desejado aspecto da capacidade de fixação simbiótica do nitrogênio atmosférico. O grão da soja é uma excelente fonte de proteína e óleo vegetal, atendendo satisfatoriamente as exigências alimentares humanas e animais. Atualmente, dos pontos de vista alimentar e econômico, é a mais importante oleaginosa cultivada no mundo (Embrapa, 2008).

A resistência à penetração é um dos atributos físicos mais adotados como indicativo da compactação do solo. Apresenta relações diretas com o crescimento das plantas, sendo mais eficiente na identificação da compactação quando acompanhado da umidade e da densidade do solo (Freddi et al., 2006). Fisicamente estabelecida pela pressão, a resistência à penetração é dada pela razão entre a força necessária para a penetração de uma base metálica do penetrômetro, provida de um cone na sua extremidade, cuja área basal é conhecida e constante. Sua avaliação deve ser concomitante à da umidade do solo, uma vez que varia de forma inversamente proporcional. Por outro lado, varia positivamente com a densidade do solo (Bengough et al., 2001). Valores de resistência à penetração considerados críticos para o crescimento radicular das plantas dependem do tipo de solo e da espécie cultivada. Entretanto, quando obtida no momento em que a umidade do solo está equivalendo a $2 / 3$ da microporosidade total (solo friável/macio), a maioria dos trabalhos adota a seguinte classificação da resistência à penetração (RP), estabelecida por Arshad et al. (1996): (a) extremamente baixa: $\mathrm{RP}<0,01 \mathrm{MPa}$; (b) muito baixa: $0,01 \leq \mathrm{RP}<0,1 \mathrm{MPa}$; (c) baixa: 0,1 $\leq \mathrm{RP}<1,0 \mathrm{MPa}$; (d) moderada: $1,0 \leq \mathrm{RP}<2,0 \mathrm{MPa}$; (e) alta: 2,0 $\leq \mathrm{RP}<4,0 \mathrm{MPa}$; (f) muito alta: 4,0 $\leq \mathrm{RP}<8,0 \mathrm{MPa}$; e (g) extremamente alta: $\mathrm{RP} \geq 8,0 \mathrm{MPa}$.

Analisando resultados de pesquisas recentes, Freddi et al. (2006) e Souza et al. (2006) mostraram que a resistência à penetração geralmente aumenta com a compactação do solo devido ao concomitante incremento da densidade e com o decréscimo da umidade. Dessa forma, seu aumento é indesejável por causar redução do crescimento radicular das plantas. Portanto, a resistência mecânica do solo à penetração tem apresentado elevada correlação com a produtividade vegetal. Freddi et al. (2006), estudando a produtividade do feijoeiro em função da resistência à penetração, encontraram representável correlação entre os dois atributos estudados.

A densidade do solo é de grande importância para os estudos agronômicos, pois permite avaliar atributos como a porosidade, condutividade hidráulica, difusividade do ar, além de ser utilizada como indicador do estado da compactação do solo (Kiehl, 1979). Pela estreita relação com outros atributos, a grande maioria das pesquisas converge para o fato de que, com o seu aumento, ocorre uma diminuição da porosidade total, macroporosidade, condutividade hidráulica, absorção iônica, e o consequente aumento da microporosidade e da resistência mecânica à 
penetração do solo. Tal fato viria a desencadear, no geral, diminuição da produtividade agrícola (Mercante et al., 2003; Secco et al., 2005; Santos et al., 2006).

Na geoestatística, a variabilidade espacial pode ser representada por mapas, confeccionados a partir de estimativas da variável estudada, sendo essa técnica definida como interpolação por krigagem, e a partir de estimativas de duas variáveis que se correlacionem (primária e secundária), denomina-se co-krigagem. Essas técnicas podem ser descritas como métodos que minimizam a variância estimada por meio de análise de regressão, levando-se em conta a dependência entre os dados distribuídos no espaço. Essas técnicas de montagem são embasadas em estimadores de variáveis regionalizadas, envolvendo estimação de pontos, ou áreas, e admitindo que as amostras são normalmente distribuídas e estacionárias. Dessa forma, são capazes de prever o fenômeno em estudo (Tragmar et al., 1985). Assim, as interpolações por krigagem e por co-krigagem estão fortemente associadas aos modelos de semivariogramas ajustados, que podem ser avaliados por meio da validação cruzada. Na sua análise, cada ponto contido dentro do domínio espacial é removido individualmente, sendo seu valor estimado por meio da krigagem como se não existisse. Portanto, pode-se construir um gráfico de valores estimados versus valores observados para todos os pontos. Do conjunto de duplas (valores estimados e valores observados) de todas as amostras, calculamse dados estatísticos básicos (média, variância dos desvios) com o objetivo de aferir a qualidade do modelo escolhido para o semivariograma (GS+, 2004).

Diante do exposto, esta pesquisa objetivou analisar a variabilidade de atributos da planta e do solo; definir as correlações lineares e espaciais entre a produtividade da soja com os atributos físicos do solo; e investigar, entre os atributos físicos do solo, aquele que melhor explique a variabilidade da produtividade da soja.

\section{MATERIAL E MÉTODOS}

O experimento foi realizado na área experimental da Fazenda de Ensino e Pesquisa - Setor de Produção Vegetal, da Faculdade de Engenharia de Ilha Solteira (FE/UNESP), localizada no município de Selvíria (MS), entre as latitudes de $20^{\circ} 18^{\prime} 05^{\prime \prime} \mathrm{S}$ e $20^{\circ} 18^{\prime} 28^{\prime \prime} \mathrm{S}$ e as longitudes de $52^{\circ} 39^{\prime} 02$ " W e $52^{\circ} 40$ ' $28^{\prime}$ "W. A precipitação média anual na região é de $1.300 \mathrm{~mm}$, e a temperatura média é de $23,7^{\circ} \mathrm{C}$, com uma altitude de $300 \mathrm{~m}$. O clima é classificado como Aw, segundo Koeppen, caracterizado como tropical úmido com estação chuvosa no verão e seca no inverno. $\mathrm{O}$ solo no qual a malha experimental foi instalada é classificado como Latossolo Vermelho distroférrico típico argiloso A moderado, hipodistrófico, álico, caulinítico, férrico, muito profundo, moderadamente ácido com declive homogêneo de 0,025 m m $\mathrm{m}^{-1}$ (Embrapa, 2006). Sua vegetação natural é do tipo Cerrado. O solo no qual foi estabelecida a pesquisa vem sendo utilizado com a sucessão das culturas do milho (verão) e feijão (inverno) há pelo menos vinte anos. De 1988 a 2003, foi realizado o preparo convencional para ambas as culturas, ao passo que de 2003 até os dias atuais foi o sistema plantio direto estabelecido sob sistema de irrigação autopropelido.

A planta-teste pesquisada foi a soja (Glycine max L. Merril), semeada no dia 30 de novembro de 2006 , após a dessecação das plantas daninhas com o herbicida glifosato, na dosagem de $1,8 \mathrm{~kg} \mathrm{ha}^{-1}$ do ingrediente ativo. O cultivar de soja semeado foi Conquista, cujo cultivo foi conduzido segundo as instruções agrícolas para as principais culturas econômicas do Estado de São Paulo (Fahl et al., 1998). O espaçamento entre linhas foi de $0,45 \mathrm{~m}$, com uma densidade final de 16 plantas por metro na linha de semeadura. Na adubação de plantio, foram utilizados $250 \mathrm{~kg} \mathrm{ha}^{-1}$ da formulação 8-28-16. Para o tratamento da semente, foi utilizado o fungicida carboxina (200 g ia $100 \mathrm{~kg}^{-1}$ de sementes) e o inoculante líquido (Rhizobium $\mathrm{sp}$ ) contendo $3.10^{9}$ células por grama de semente. O tratamento fitossanitário, realizado em diversas etapas, foi o seguinte: (a) em 20/12/2006 foi aplicado o herbicida bentazona (600 $\mathrm{g} \mathrm{ha}^{-1}$ do ia); (b) em 26/12/2006 foram aplicados o herbicida fenoxaprope-p-etílico (50 $\mathrm{g} \mathrm{ha}^{-1}$ do ia) e o inseticida cipermetrina (200 $\mathrm{g} \mathrm{ha}^{-1}$ do ia); e (c) em 28/01/2007 e em 15/02/2007 foram aplicados, em cada um dos dias, o fungicida tebuconazole (100 $\mathrm{g} \mathrm{ha}^{-1}$ do ia) e o inseticida endosulfan (525 $\mathrm{g} \mathrm{ha}^{-1}$ do ia).

Foram definidas as direções $\mathrm{x}$ e $y$ do sistema de coordenadas cartesianas num lançante da cultura da soja. Para isso, foi utilizado o nível ótimo comum, efetuando-se o estaqueamento global da malha experimental no final do ciclo da cultura da soja, no dia 14 de março de 2007. A grande malha experimental foi constituída de 6 linhas e 12 colunas, de formato retangular e contendo 72 pontos amostrais, espaçados de $8 \mathrm{em} 8 \mathrm{~m}$ em ambos os eixos. Tais eixos, que foram as maiores transeções e contendo 16 pontos cada, tiveram $88 \mathrm{~m}$, cuja hipotenusa foi de 96,66 m. Assim, a área global do estudo foi de $4.608 \mathrm{~m}^{2}$. Entretanto, foram alocadas por sorteio, dentro da grande malha, mais três submalhas de refinamento da distância entre os pontos, visando detalhar o estudo da dependência espacial dos dados para espaçamento entre pontos menores do que $8 \mathrm{~m}$. Cada submalha teve pontos espaçados de 2,67 em 2,67 m. Como elas adicionaram mais 48 pontos amostrais, o total foi de 120.

Os atributos pesquisados do solo e da planta foram todos individualmente coletados no entorno de cada ponto amostral da malha experimental. Os atributos do solo foram: (a) densidade do solo (DS), (b) resistência à penetração (RP), (c) umidade gravimétrica (UG), e (d) umidade volumétrica (UV), coletados em maio de 2007 em duas profundidades, a saber: (a) $0-0,10 \mathrm{~m} \mathrm{e}$ 
(b) $0,10-0,20 \mathrm{~m}$. O da planta foi a produtividade de grãos (PG), coletada em quatro linhas de semeadura, as quais abrigaram uma largura de $1,80 \mathrm{~m}$ e uma área útil de $3,24 \mathrm{~m}^{2}$, realizada na colheita em 21/03/ 2007.

As amostras de solo, originadas de monólitos com estruturas preservadas, foram para a DS e a UV. Dessa forma, a densidade do solo foi determinada pelo Método do Anel Volumétrico, expressa em $\left(\mathrm{kg} \mathrm{dm}^{-3}\right)$, enquanto a umidade gravimétrica foi determinada com balança analítica, com precisão de +/- 0,005 g, expressa em $\left(\mathrm{kg} \mathrm{kg}^{-1}\right)$. Todas foram determinadas conforme Embrapa (1997). A UV foi determinada pelo seguinte cálculo, relacionado em Kiehl (1979):

$$
\mathrm{UV}=\mathrm{UG} \times \mathrm{DS}
$$

em que UV é a umidade volumétrica $\left(\mathrm{m}^{3} \mathrm{~m}^{-3}\right)$, UG é a umidade gravimétrica $\left(\mathrm{kg} \mathrm{kg}^{-1}\right)$, e DS é a densidade do solo $\left(\mathrm{kg} \mathrm{dm}^{-3}\right)$. Os dados da RP foram obtidos com o penetrômetro de impactos e calculados segundo a seguinte expressão (Souza et al., 2001):

$$
\mathrm{RP}=\{5,581+6,891 \times[\mathrm{N} /(\mathrm{P}-\mathrm{A}) \times 10]\} \times 0,0981
$$

em que RP é a resistência mecânica do solo à penetração [MPa], Né o número de impactos efetuados com o martelo do penetrômetro para a obtenção da leitura, A e P são, respectivamente, as leituras antes e depois da realização dos impactos [cm]. Tais determinações foram efetuadas no Laboratório de Análises Físicas do Solo da Faculdade de EngenhariaFEI/UNESP/Campus de Ilha Solteira.

Para cada atributo estudado, efetuou-se a análise descritiva clássica, com auxílio do software estatístico SAS (Schlotzhaver \& Littell, 1997), em que foram calculados a média, a mediana, valores mínimo e máximo, o desvio-padrão, o coeficiente de variação, a curtose, e a assimetria e distribuição de frequência. Posteriormente, realizou-se a identificação dos outliers, efetuando a substituição dos seus valores pelo valor médio dos circunvizinhos contidos na malha. Para testar a hipótese de normalidade, ou de lognormalidade, realizou-se o teste de Shapiro \& Wilk (1965) a $1 \%$.

Foi montada a matriz de correlação, objetivando efetuar as correlações lineares simples para as combinações, duas a duas, entre todos os atributos estudados. Assim, selecionaram-se aqueles de maior correlação linear e que, portanto, poderiam apresentar semivariograma cruzado e a consequente co-krigagem. Isoladamente para cada atributo, foi analisada sua dependência espacial pelo cálculo do semivariograma simples. Contudo, para aqueles que apresentaram interdependência espacial, calcularam-se também seus semivariogramas cruzados, com base nos pressupostos de estacionaridade da hipótese intrínseca pelo uso do pacote Gamma Design Software (GS+, 2004). Os ajustes dos semivariogramas simples e cruzados, em função de seus modelos, foram efetuados prioritariamente pela seleção inicial de: (a) menor soma dos quadrados dos desvios (RSS); (b) maior coeficiente de determinação $\left(\mathrm{r}^{2}\right)$; e (c) maior avaliador da dependência espacial (ADE). A decisão final do modelo que representou o ajuste foi realizada pela validação cruzada, assim como para a definição do tamanho da vizinhança que proporcionou a melhor malha de krigagem e, ou, co-krigagem, realizadas por meio da krigagem em blocos. Para cada atributo, foram relacionados o efeito pepita (Co), o alcance (Ao) e o patamar $(\mathrm{Co}+\mathrm{C})$. A análise do avaliador da dependência espacial (ADE) foi efetuada conforme a seguinte expressão (GS+, 2004):

$$
\mathrm{ADE}=[\mathrm{C} /(\mathrm{C}+\mathrm{Co})] 100
$$

em que ADE é o avaliador da dependência espacial; C é a variância estrutural; e C + Co é o patamar. A interpretação proposta para o $\mathrm{ADE}$ foi a seguinte: $\mathrm{ADE} \leq 25 \%$ indica variável espacial fracamente dependente; $25 \%<\mathrm{ADE} \leq 75 \%$ indica variável espacial moderadamente dependente; e ADE > $75 \%$ indica variável espacial fortemente dependente. Sabese, porém, que a validação cruzada é uma ferramenta destinada a avaliar modelos alternativos de semivariogramas simples e cruzados, que efetuarão, respectivamente, a krigagem e a co-krigagem. $\mathrm{Na}$ sua análise, cada ponto contido dentro do domínio espacial é removido individualmente, sendo seu valor estimado como se ele não existisse. Dessa forma, podese construir um gráfico de valores estimados versus valores observados para todos os pontos. $\mathrm{O}$ coeficiente de correlação (r) entre tais valores reflete a eficiência do ajuste dado pela técnica da soma dos quadrados dos desvios, representando a equação de regressão linear em questão. Um ajuste perfeito teria o coeficiente de regressão igual a 1 e a linha do melhor ajuste coincidiria com o modelo perfeito, isto é, com o coeficiente linear igual a zero e o angular igual a 1 (GS+, 2004). Assim, trabalhando-se na obtenção do número ideal de vizinhos, foram obtidos, por meio da interpolação, os mapas de krigagem e de co-krigagem para análise da dependência e da interdependência espacial entre os atributos.

\section{RESULTADOS E DISCUSSÃO}

A variabilidade de um atributo pode ser classificada conforme a magnitude do seu coeficiente de variação (Freddi et al., 2006). Portanto, no quadro 1 a produtividade de grãos (PG) apresentou média variabilidade, com coeficiente de variação de $14 \%$. Assim, esse dado foi menor que o de Johann et al. (2004), que os apresentaram com alta variabilidade (23 \%), quando trabalharam com um Latossolo Bruno Distrófico de Cascavel (PR).

A resistência à penetração $(\mathrm{RP})$ apresentou-se com média variabilidade em ambos os casos, sendo de $16 \mathrm{e}$ 
Quadro 1. Análise descritiva inicial de alguns atributos da produtividade de soja e de um Latossolo Vermelho distroférrico de Selvíria (MS)

\begin{tabular}{|c|c|c|c|c|c|c|c|c|c|c|}
\hline \multirow{4}{*}{ Atributo $^{(1)}$} & \multicolumn{10}{|c|}{ Medida estatística descritiva } \\
\hline & \multirow[t]{3}{*}{ Média 1} & \multirow[t]{3}{*}{ Mediana } & \multicolumn{2}{|c|}{ Valor } & \multirow[t]{3}{*}{ Desvio-padrão } & \multicolumn{3}{|c|}{ Coeficiente de variação } & \multirow{2}{*}{\multicolumn{2}{|c|}{$\begin{array}{c}\text { Probabilidade } \\
\text { do teste } \\
(2)\end{array}$}} \\
\hline & & & \multirow[t]{2}{*}{ Mínimo } & \multirow[t]{2}{*}{ Máximo } & & \multirow{2}{*}{$\begin{array}{c}\text { Variação } \\
(\%)\end{array}$} & \multirow[t]{2}{*}{ Curtose } & \multirow[t]{2}{*}{$\overline{\text { Assimetria }}$} & & \\
\hline & & & & & & & & & $\operatorname{Pr}<\mathrm{w}$ & $\mathrm{DF}$ \\
\hline PG $\left(\mathrm{kg} \mathrm{ha}^{-1}\right)$ & 3317,5 & 3304,4 & 2408,2 & 4566,3 & 455,136 & 13,7 & $-0,408$ & 0,018 & 0,486 & $\mathrm{NO}$ \\
\hline $\mathrm{DS} 1\left(\mathrm{~kg} \mathrm{dm}^{-3}\right)$ & 1,401 & 1,400 & 1,240 & 1,553 & 0,064 & 4,6 & $-0,503$ & $-0,139$ & 0,599 & NO \\
\hline $\mathrm{DS} 2\left(\mathrm{~kg} \mathrm{dm}^{-3}\right)$ & 1,383 & 1,385 & 1,247 & 1,487 & 0,055 & 3,9 & $-0,608$ & $-0,126$ & 0,235 & NO \\
\hline RP1 (MPa) & 3,109 & 3,068 & 1,968 & 4,278 & 0,484 & 15,6 & $-0,202$ & 0,103 & 0,579 & $\mathrm{NO}$ \\
\hline RP2 (MPa) & 3,603 & 3,572 & 2,227 & 5,054 & 0,515 & 14,3 & 0,226 & 0,040 & 0,892 & $\mathrm{NO}$ \\
\hline UG1 (kg kg-1) & 0,225 & 0,225 & 0,201 & 0,249 & 0,010 & 4,4 & $-0,177$ & 0,280 & 0,272 & $\mathrm{NO}$ \\
\hline UG2 (kg kg·-1) & 0,240 & 0,240 & 0,224 & 0,264 & 0,007 & 3,0 & 0,762 & 0,324 & 0,091 & $\mathrm{NO}$ \\
\hline $\mathrm{UV} 1\left(\mathrm{~m}^{3} \mathrm{~m}^{-3}\right)$ & 0,315 & 0,317 & 0,272 & 0,356 & 0,019 & 6,1 & $-0,660$ & $-0,103$ & 0,289 & $\mathrm{NO}$ \\
\hline $\mathrm{UV} 2\left(\mathrm{~m}^{3} \mathrm{~m}^{-3}\right)$ & 0,332 & 0,333 & 0,299 & 0,375 & 0,015 & 4,5 & $-0,064$ & $-0,054$ & 0,539 & NO \\
\hline
\end{tabular}

(1) PG: produtividade de grãos de soja; DS, RP, UG e UV, de 1 a 2, são respectivamente a densidade do solo, resistência à penetração, umidade gravimétrica e umidade volumétrica do solo. ${ }^{(2)} \mathrm{DF}$ : distribuição de frequência, sendo NO do tipo normal.

$14 \%$, respectivamente, em profundidade (Quadro 1). Esses dados concordaram com aqueles de Mercante et al. (2003), Johann et al. (2004) e Freddi et al. (2006), respectivamente, de $15 \%$ obtido num Latossolo Vermelho distroférrico, 16 \% num Latossolo Bruno distrófico e de 14 \% num Latossolo Vermelho distrófico. Contudo, discordaram de Imhoff et al. (2000), Souza et al. (2001, 2006) e Carvalho et al. (2002), os quais variaram entre alto e muito alto, respectivamente com valores de $71 \%$ obtidos num Nitossolo Vermelho eutrófico, 21-38 \% e de 51-110 \% num Latossolo Vermelho distrófico.

Em relação à densidade do solo (DS), à umidade gravimétrica (UG) e à umidade volumétrica (UV), todos apresentaram baixa variabilidade, com coeficientes de variação entre 3 e $6 \%$. Assim, tais dados concordaram com aqueles de Imhoff et al. (2000), Souza et al. (2001), Carvalho et al. (2002), Mesquita et al. (2003), Johann et al. (2004), Secco et al. (2005) e Santos et al. (2006), os quais variaram entre 4 e $9 \%$. Contudo, somente em relação à UG, tais dados discordaram apenas dos de Imhoff et al. (2000) e de Carvalho et al. (2002), cujas médias foram, respectivamente, de 11 e $16 \%$ (Quadro 1).

Quando uma variável estatística qualquer possuir distribuição de frequência do tipo normal, a medida de tendência central mais adequada para representála deve ser a média. Em contrapartida, o será pela mediana, ou pela média geométrica, caso possua distribuição de frequência do tipo lognormal (Spiegel, 1985). Portanto, para todos os atributos estudados, as respectivas medidas de tendência central deverão ser representadas pelos valores médios. Isso porque todos eles apresentaram distribuição de frequência do tipo normal, com coeficientes de assimetria positiva entre 0,018 e 0,324 , assim como a negativa entre $-0,139$ e -0,054. Já os coeficientes de curtose positiva ficaram entre 0,226 e 0,762, assim como as negativas entre -0,660 e -0,064. Contudo, e independentemente de tais coeficientes, todos foram significativos a $5 \%$ pelo teste de normalidade de Shapiro \& Wilk (1965), uma vez que a respectiva probabilidade variou entre 0,091 e 0,892 (Quadro 1). Dessa forma, a distribuição de frequência do tipo normal de todos os atributos estudados, de acordo com os autores, foi o seguinte: (a) PG (Santos et al., 2005; Marins, 2006; Carvalho et al., 2006; Freddi et al., 2006; Santos et al., 2006), (b) DS (Mesquita et al., 2003; Marins, 2006; Santos et al, 2006), (c) RP (Marins, 2006; Souza et al., 2006), (d) UG (Carvalho et al., 2006; Freddi et al., 2006), e (e) UV (Marins, 2006).

No quadro 1 , o valor médio da $P G$ foi de $3.317,5 \mathrm{~kg} \mathrm{ha}^{-1}$, ficando muito próximo daquele relatado por Secco et al. (2004), que foi de $3.373 \mathrm{~kg} \mathrm{ha}^{-1}$, quando utilizados seis cultivares de soja submetidos a diferentes estados de compactação no sistema plantio direto. Neste trabalho, o valor médio ficou 18,1\% acima da média nacional, que foi de $2.809 \mathrm{~kg} \mathrm{ha}^{-1}$ para a safra de 2006/2007 (Embrapa, 2008). Oliveira \& Moniz (1975) efetuaram o levantamento pedológico detalhado dos solos da Estação Experimental do Instituto Agronômico do Estado de São Paulo, localizada em Ribeirão Preto, e encontraram, em um Latossolo Vermelho distroférrico virgem e sob mata natural, valores da porosidade total e da densidade, originados da seção de controle do perfil do solo entre 0,582 e $0,671 \mathrm{~m}^{3} \mathrm{~m}^{-3}$ e de 0,98 e $1,13 \mathrm{~kg} \mathrm{dm}^{-3}$, respectivamente. Portanto, com base nessa 
caracterização, os valores médios da densidade do solo deste estudo, 1,401 $\mathrm{kg} \mathrm{dm}^{-3}$ (DS1) e 1,383 kg dm-3 (DS2), apresentaram uma magnitude que indicou compactação do solo nas camadas estudadas, uma vez que seu menor valor foi substancialmente superior (1,223 vez) ao maior valor obtido em solo natural para o mesmo solo em questão. Outrossim, no sistema plantio direto tal compactação é originada pelo trânsito das máquinas e implementos agrícolas, assim como pelo tempo de adoção deste sistema, sem que seja efetuada uma prática conservacionista do solo que venha a reverter esse problema. Dessa forma, tais dados ficaram de acordo com aqueles da pesquisa de Secco et al. (2004), que encontraram valores de densidade do solo semelhantes e, ou, superiores a $1,45 \mathrm{~kg} \mathrm{dm}^{-3}$, também em um Latossolo Vermelho distroférrico.

Bengough et al. (2001) relataram que a condição ideal de umidade do solo para a coleta dos dados de resistência à penetração deve ser quando ela estiver variando entre a capacidade de campo e até com um terço a menos de água, isto é, quando o solo ideal, conceituado por Kiehl (1979), apresentar uma umidade volumétrica na microporosidade variando entre 0,33 e $0,22 \mathrm{~m}^{3} \mathrm{~m}^{-3}$. Portanto, uma vez que a capacidade de campo do solo em questão foi de $0,351 \mathrm{~m}^{3} \mathrm{~m}^{-3}$, devese salientar que os dados desta pesquisa foram coletados em ótimas condições de umidade volumétrica do solo, uma vez que seus valores ficaram entre $0,315 \mathrm{~m}^{3} \mathrm{~m}^{-3}$ (RP1) e 0,332 $\mathrm{m}^{3} \mathrm{~m}^{-3}$ (RP2). Porém, quando utilizada a classificação de Arshad et al. (1996), os altos valores da resistência à penetração do solo (3,109 e 3,603 MPa, respectivamente para RP1 e RP2) corroboraram que o solo estudado encontrava-se compactado, de forma a suscitar que a produtividade de soja deste estudo pôde também não ter atingido seu máximo potencial, uma vez que pôde ter ocorrido impedimento mecânico ao desenvolvimento de suas raízes (Quadro 1).

Beutler et al. (2006) analisaram a cultura da soja (cv. Conquista) em função do grau de compactação de um Latossolo Vermelho distrófico de Jaboticabal (SP) e observaram produtividade máxima de $1.326 \mathrm{~kg} \mathrm{ha}^{-1}$, equivalente à resistência à penetração do solo de 2,95 $\mathrm{MPa}$. Beutler et al. (2007) também analisaram a cultura da soja (cv. IAC Foscarim 31) em função do grau de compactação de um Latossolo Vermelho eutroférrico de Jaboticabal (SP) e observaram produtividades máximas de $3.175 \mathrm{~kg} \mathrm{ha}^{-1}$, equivalente à resistência à penetração do solo de $1,30 \mathrm{MPa}$, e $3.261 \mathrm{~kg} \mathrm{ha}^{-1}$, correspondente à densidade do solo de $1,26 \mathrm{~kg} \mathrm{dm}^{-3}$. Portanto, em relação aos referidos trabalhos, os dados da PG, RP e da DS deste estudo (Quadro 1) tiveram as seguintes performances: a PG média (3.318 $\left.\mathrm{kg} \mathrm{ha}^{-1}\right)$ foi 2,5 vezes superior àquela observada por Beutler et al. (2006) e 1,02 vez superior àquela relatada por Beutler et al. (2007); a RP média obtida (3,386 MPa) foi 1,15 vez superior àquela citada por Beutler et al. (2006), assim como 2,60 vezes superior à encontrada por Beutler et al. (2007).
Também, a DS média obtida (1,392 $\left.\mathrm{kg} \mathrm{dm}^{-3}\right)$ foi 1,11 vez superior àquela de Beutler et al. (2007). Nesta pesquisa, obteve-se uma PG média de grãos de soja superior àquelas de Beutler et al. (2006, 2007), em solo com condições físicas mais severas. Uma vez que o solo pesquisado encontrava-se substancialmente mais compactado do que nas referidas condições, podese inferir que outros fatores, que não a RP e a DS, limitaram de forma decisiva as produtividades de soja obtidas por Beutler et al. (2006, 2007).

A umidade gravimétrica (Quadro 1) apresentou valores de $0,225 \mathrm{~kg} \mathrm{~kg}^{-1}$ (UG1) e de $0,240 \mathrm{~kg} \mathrm{~kg}^{-1}$ (UG2), concordando com os estudos de Carvalho et al. (2002) e Freddi et al. (2006), que apresentaram aumento desses valores em profundidade do solo. Por outro lado, ficou diretamente relacionada com os aumentos da UV, que foram de $0,315 \mathrm{~m}^{3} \mathrm{~m}^{-3}$ (UV1) e de $0,332 \mathrm{~m}^{3} \mathrm{~m}^{-3}$ (UV2).

No quadro 2, a correlação entre a PG e os atributos do solo apresentou significância exclusivamente para os pares: (1) PG x DS2 ( $\left.\mathrm{r}=-0,213^{*}\right)$ e (2) PG x RP2 $\left(r=-0,191^{*}\right)$. No primeiro e segundo pares, respectivamente, suas correlações foram inversas, indicando que, com aumento da DS2 e da RP2, ocorrerá a diminuição da produtividade de soja. Portanto, em relação à DS, esse resultado ficou de acordo com os trabalhos de Santos et al. (2006) e de Lima et al. (2007), que, respectivamente trabalhando com a produtividade de grãos de milho (Latossolo Vermelho distroférrico de Selvíria, MS) e a produtividade de matéria seca da forragem do milho safrinha (Latossolo Vermelho distrófico de Pereira Barreto, SP), obtiveram correlações inversas e significativas com a densidade do solo, respectivamente de $-0,212^{*}$ e - $0,143^{*}$. Já em relação à $\mathrm{RP}$, esse resultado também ficou de acordo com os dados de Freddi et al. (2006), que, trabalhando com a produtividade de grãos de milho (Latossolo Vermelho distrófico de Selvíria, MS), obtiveram uma correlação inversa e significativa, com resistência à penetração $(r=-0,170 *)$.

No geral, as correlações entre os pares de atributos do solo (Quadro 2) apresentaram-se, quando analisados dois atributos quaisquer dentro da mesma profundidade, com o sinal positivo (correlação direta) ou negativo (correlação indireta) para todas aquelas estabelecidas nas duas profundidades. Os de correlação direta, com os respectivos valores do coeficiente de correlação, foram o DS x RP $\left(0,338^{* *}\right.$ a $\left.0,275^{* *}\right)$, DS x UV $\left(0,761^{* *}\right.$ a $\left.0,206^{*}\right)$, e UG x UV $\left(0,660^{* *}\right.$ a $\left.0,272^{* *}\right)$. Já os de correlação indireta foram o DS x UG $\left(-0,211^{*}\right.$ a $\left.-0,184^{*}\right)$ e RP x UG $\left(-0,286^{* *}\right.$ a $\left.-0,185^{*}\right)$.

No quadro 2, o par RP x UG apresentou correlação inversa entre seus atributos, corroborando a teoria pedológica. Assim, com o aumento da UG ocorrerá diminuição da RP, e vice-versa, o que está de acordo com o resultado relatado por Santos et al. (2005), que, trabalhando com a produtividade de grãos de feijão num Latossolo Vermelho distrófico de Selvíria (MS), 
Quadro 2. Matriz de correlação linear simples entre a produtividade de grãos de soja e alguns atributos físicos de um Latossolo Vermelho distroférrico de Selvíria (MS)

\begin{tabular}{|c|c|c|c|c|c|c|c|c|}
\hline \multirow{2}{*}{ Atributo $^{(1)}$} & \multicolumn{8}{|c|}{ Coeficiente de correlação $^{(2)}$} \\
\hline & $\mathbf{P G}$ & DS1 & DS2 & RP1 & RP2 & UG1 & UG2 & UV1 \\
\hline DS1 & $-0,101$ & & & & & & & \\
\hline $\mathrm{DS} 2$ & $-0,213^{*}$ & $0,258^{* *}$ & & & & & & \\
\hline $\mathrm{RP} 1$ & $-0,005$ & $0,295^{* *}$ & $0,275^{* *}$ & & & & & \\
\hline RP2 & $-0,191^{*}$ & 0,152 & $0,338^{* *}$ & $0,344^{* *}$ & & & & \\
\hline UG1 & 0,057 & $-0,077$ & 0,002 & $-0,185^{*}$ & $-0,078$ & & & \\
\hline UG2 & 0,102 & $-0,211^{*}$ & $-0,184^{*}$ & $-0,286^{* *}$ & $-0,194^{*}$ & $0,607^{* *}$ & & \\
\hline UV1 & $-0,045$ & $0,695^{* *}$ & $0,206^{*}$ & 0,092 & 0,065 & $0,660 * *$ & $0,272^{* *}$ & \\
\hline UV2 & $-0,123$ & 0,092 & $0,761^{* *}$ & 0,054 & 0,166 & $0,399 * *$ & $0,497^{* *}$ & $0,361^{* *}$ \\
\hline
\end{tabular}

(1) PG: produtividade de grãos, DS, RP, UG e UV, de 1 a 2 , são respectivamente a densidade do solo, resistência à penetração, umidade gravimétrica e umidade volumétrica do solo. ${ }^{(2) * *}$ e *: significativos a 1 e $5 \%$.

também obtiveram correlação inversa entre eles $(\mathrm{r}=$ $-0,351^{* *}$ a $\left.-0,208^{*}\right)$. Porém está diferente daquele de Carvalho et al. (2006), que, também trabalhando com a produtividade de grãos de feijão num Latossolo Vermelho distroférrico de Selvíria (MS), obtiveram correlação direta $\left(r=0,161^{*}\right.$ a $\left.0,171^{*}\right)$. Esses últimos resultados discordaram da teoria pedológica, o que pode ser justificado pelo curto tempo de utilização do sistema plantio direto.

No âmbito da correlação entre atributo da planta versus solo (Quadro 2), os modelos matemáticos $\mathrm{PG}=$ $\mathrm{f}(\mathrm{DS} 2)$ e $\mathrm{PG}=\mathrm{f}(\mathrm{RP} 2)$, respectivamente representados na figura $1 \mathrm{a}, \mathrm{b}$, apresentaram-se com uma variação indireta entre causa e efeito, respectivamente do tipo potencial e linear, com coeficientes de correlação entre $-0,198^{*}$ e $-0,213^{*}$. Tais modelos diferiram do modelo quadrático obtido por Beutler et al. (2006, 2007), quando pesquisaram a produtividade da soja em função da DS e da RP, em dois latossolos distintos de Jaboticabal (SP). Especificamente em relação ao modelo $P G=f(D S 2)$, que entre todos os atributos do solo apresentou a maior correlação com a PG, para o menor valor da DS2 (1,247 $\left.\mathrm{kg} \mathrm{dm}^{-3}\right)$, a PG estimada foi de $3.560 \mathrm{~kg} \mathrm{ha}^{-1}$, assim como para o maior $\left(1,487 \mathrm{~kg} \mathrm{dm}^{-3}\right)$, foi de $3.135 \mathrm{~kg} \mathrm{ha}^{-1}$. Dessa forma, pela análise de regressão $\mathrm{PG}=$ (atributos do solo), 0 DS2 apresentou-se como um plausível indicador da qualidade física do solo estudado.

Ficou atestado que, com exceção da DS1, RP2 e UG2, que apresentaram efeito de pepita puro, todos os demais atributos apresentaram dependência espacial (Quadro 3, Figura 2). Observa-se, nos semivariogramas, que o coeficiente de determinação espacial $\left(\mathrm{r}^{2}\right)$ decresce na seguinte ordem: (1) DS2 (0,959), (2) RP1 (0,930), (3) PG (0,879), (4) UG1 (0,837), (5) UV1 (0,816), e (6) UV2 (0,466). Assim, em relação aos três primeiros, que tiveram elevados coeficientes de determinação espacial, observou-se o seguinte: DS2, seu $\mathrm{r}^{2}(0,959)$, que indicou ser tal atributo o de melhor ajuste semivariográfico, concordou com aqueles observados por Santos et al. (2006) e Lima et al. (2007), nos quais variaram entre 0,819 e 0,906. Em relação ao $\mathrm{ADE}$, o moderado valor observado (44,9\%) também concordou com o dos referidos autores, que variaram

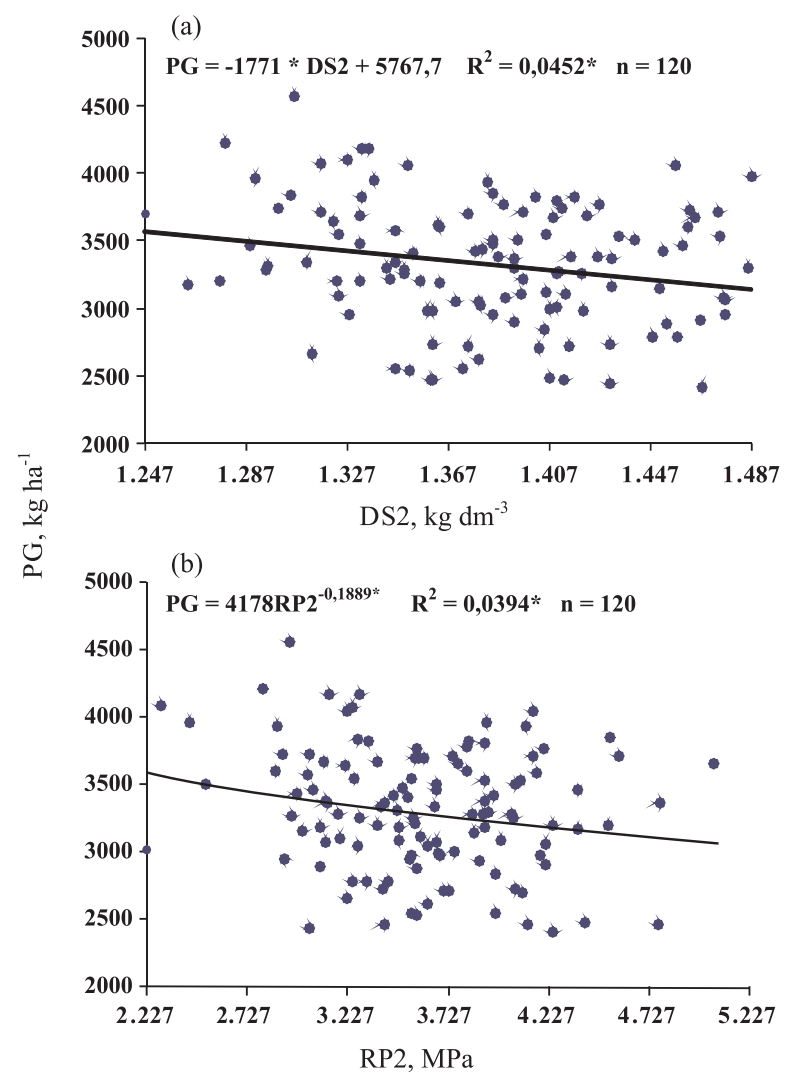

Figura 1. Equações de regressão da produtividade da soja em função de alguns atributos físicos de um Latossolo Vermelho distroférrico de Selvíria (MS). 
entre 50,1 e 72,2\%. O modelo gaussiano ajustado para o DS2 ficou de acordo com o observado por Lima et al. (2007), diferentemente do modelo esférico obtido por Santos et al. (2006). Também, o alcance do DS2 do presente $(9,0 \mathrm{~m})$ foi menor do que aqueles dos citados autores, que variaram entre 23,0 e $60,6 \mathrm{~m}$.

Para o RP1 (Quadro 3), seu r 20,930$)$ indicou ser tal atributo o segundo de melhor ajuste semivariográfico, concordando com aqueles observados por Santos et al. (2005), Carvalho et al. (2006) e Freddi et al. (2006), que variaram entre 0,881 e 0,941. Em relação ao $\mathrm{ADE}$, o moderado valor observado (60,1 \%) concordou os de Carvalho et al. (2006) e Freddi et al. (2006), que variaram entre 42,9 e 73,6 \%, discordando, contudo, dos de Santos et al. (2005), que obtiveram o valor de $77,3 \%$. O modelo esférico ajustado para o RP1 ficou de acordo com o observado por Santos et al. (2005) e Carvalho et al. (2006), diferentemente do modelo exponencial obtido por Freddi et al. (2006). Também, o alcance do RP1 deste estudo (11,5 m) foi menor do que aquele citado por todos os autores citados, que variaram entre 20,2 e 67,1 m.

Para a PG (Quadro 3), seu $\mathrm{r}^{2}(0,879)$ indicou ser tal atributo o terceiro de melhor ajuste semivariográfico, concordando com aqueles de Santos et al. (2005) e Santos et al. (2006), que variaram entre 0,868 e 0,958 , assim como discordou dos menores valores observados por Carvalho et al. (2006) e Freddi et al. (2006), que variaram entre 0,598 e 0,798. Em relação ao $\mathrm{ADE}$, o moderado valor observado (54,7 \%) concordou com os de Santos et al. (2005) e Santos et al. (2006), que variaram entre 50,1 e 73,1\%, assim como discordou dos de Carvalho et al. (2006) e Freddi et al. (2006), que variaram entre 80,0 e $82,1 \%$. O modelo esférico ajustado para a PG ficou de acordo com o observado por Carvalho et al. (2006) e Santos et al. (2006), diferentemente do modelo exponencial obtido por Santos et al. (2005) e Freddi et al. (2006). Também o alcance da PG deste estudo (19,7 m) foi maior do que o do valor obtido por Santos et al. (2005) e Freddi et al. (2006), que variaram entre 6,1 e 15,3 m, assim como foi menor do que aqueles encontrados por Carvalho et al. (2006) e Santos et al. (2006), que variaram entre 20,2 e $41,1 \mathrm{~m}$.

No quadro 3, observa-se que a relação decrescente dos alcances foi a seguinte: (1) PG (19,7 m), (2) UV1 (13,0 m), (3) UG1 (12,5 m), (4) RP1 (11,5 m), (5) DS2 $(9,0 \mathrm{~m})$ e (6) UV2 (7,1 m). Nesta pesquisa, visando auxiliar outros trabalhos, os valores dos alcances a serem utilizados nos pacotes geoestatísticos que alimentarão os pacotes computacionais empregados na agricultura de precisão em geral não devem ser menores do que $7,1 \mathrm{~m}$, e, exclusivamente para o atributo da planta, não menor do que $19,7 \mathrm{~m}$.

Na figura 2a, observa-se no mapa de krigagem que os maiores valores de produtividade de grãos de soja (PG) (3.318-3.729 kg ha-1) ocorreram em forma de cruz, com o travessão horizontal estabelecido no sentido nordeste-sudoeste, e com o vertical no sentido noroeste-sul. Nas demais regiões, a produtividade variou entre 2.770 e $3.318 \mathrm{~kg} \mathrm{ha}^{-1}$. Em relação aos atributos do solo, foi notada, com respeito à $\mathrm{PG}$ (Figura 2a), semelhança inversa e elevada com o comportamento espacial da UV2 (Figura 2f). Nos sítios

Quadro 3. Parâmetros dos semivariogramas simples e cruzados ajustados para alguns atributos da produtividade da soja e de um Latossolo Vermelho distroférrico de Selvíria (MS)

\begin{tabular}{cccccccc}
\hline Modelo $^{(1)}$ & \multicolumn{7}{c}{ Parâmetro } \\
\cline { 2 - 6 } & Modelo $^{(2)}$ & $\begin{array}{c}\text { Efeito pepita } \\
\left(\mathrm{C}_{0}\right)\end{array}$ & $\begin{array}{c}\text { Patamar } \\
\left(\mathrm{C}_{0}+\mathrm{C}\right)\end{array}$ & $\begin{array}{c}\text { Alcance } \\
\left(\mathrm{A}_{0}\right)\end{array}$ & $\mathbf{R}^{2}$ & $\mathrm{SQR}^{(3)}$ & $\begin{array}{c}\text { Avaliador da } \\
\text { dependência } \\
\text { espacial }\end{array}$ \\
& & & & $\frac{\mathrm{ADE}^{(4)}}{\mathrm{Classe}}$ \\
\hline
\end{tabular}

$\mathrm{m}$

$\mathrm{y}(\mathrm{h})$ simples dos atributos da planta e do solo

\begin{tabular}{|c|c|c|c|c|c|c|c|c|}
\hline PG $\left(\mathrm{kg} \mathrm{ha}^{-1}\right)$ & esf & $7,010.10^{4}$ & $1,546.10^{5}$ & 19,7 & 0,879 & $8,98 \cdot 10^{8}$ & 54,7 & moderada \\
\hline $\mathrm{DS} 2\left(\mathrm{~kg} \mathrm{dm}^{-3}\right)$ & gau & $1,323.10^{-3}$ & $2,400.10^{-3}$ & 9,0 & 0,959 & $3,122 \cdot 10^{-8}$ & 44,9 & moderada \\
\hline RP1 (MPa) & esf & $8,530 \cdot 10^{-2}$ & $2,126 \cdot 10^{-4}$ & 11,5 & 0,930 & $5,138.10^{-4}$ & 60,1 & moderada \\
\hline UG1 (kg kg-1) & esf & $3,600.10^{-5}$ & $9,110.10^{-5}$ & 12,5 & 0,837 & $2,974.10^{-10}$ & 60,5 & moderada \\
\hline $\mathrm{UV} 1\left(\mathrm{~m}^{3} \mathrm{~m}^{-3}\right)$ & $\exp$ & $1,070.10^{-4}$ & $3,160 \cdot 10^{-4}$ & 13,0 & 0,816 & $2,922.10^{-9}$ & 66,1 & moderada \\
\hline $\mathrm{UV} 2\left(\mathrm{~m}^{3} \mathrm{~m}^{-3}\right)$ & gau & $1,133.10^{-4}$ & $1,900.10^{-4}$ & 7,1 & 0,466 & $2,569 \cdot 10^{-9}$ & 40,4 & moderad \\
\hline \multicolumn{9}{|c|}{$y(h)$ cruzados entre atributos da planta e do solo } \\
\hline $\mathrm{P} 1$ = f(UG1) & esf & $-1,000.10^{-6}$ & $-1,031.10^{-3}$ & 15,4 & 0,494 & $7,897-.10^{-7}$ & 99,9 & alta \\
\hline$G=f(U V 2)$ & esf & $-1,410.10^{-1}$ & $-6,740.10^{-1}$ & 18,2 & 0,674 & $-6,980.10^{-1}$ & 79,1 & alta \\
\hline
\end{tabular}

(1) PG: produtividade de grãos de soja, DS: densidade do solo, RP: resistência à penetração, UG: umidade gravimétrica e UV: umidade volumétrica. ${ }^{(2)}$ exp: exponencial, gau: gaussiano, esf: esférico. ${ }^{(3)}$ SQR: soma dos quadrados dos resíduos. ${ }^{(4)}$ ADE: avaliador da dependência espacial (\%). 


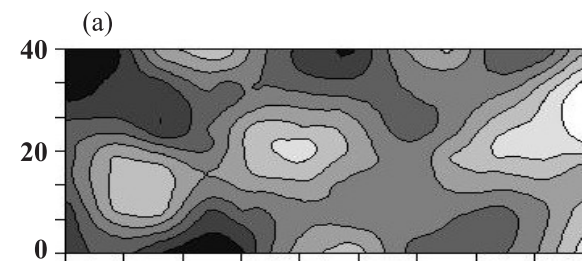

PG, $\mathrm{kg} \mathrm{ha}^{-1}$
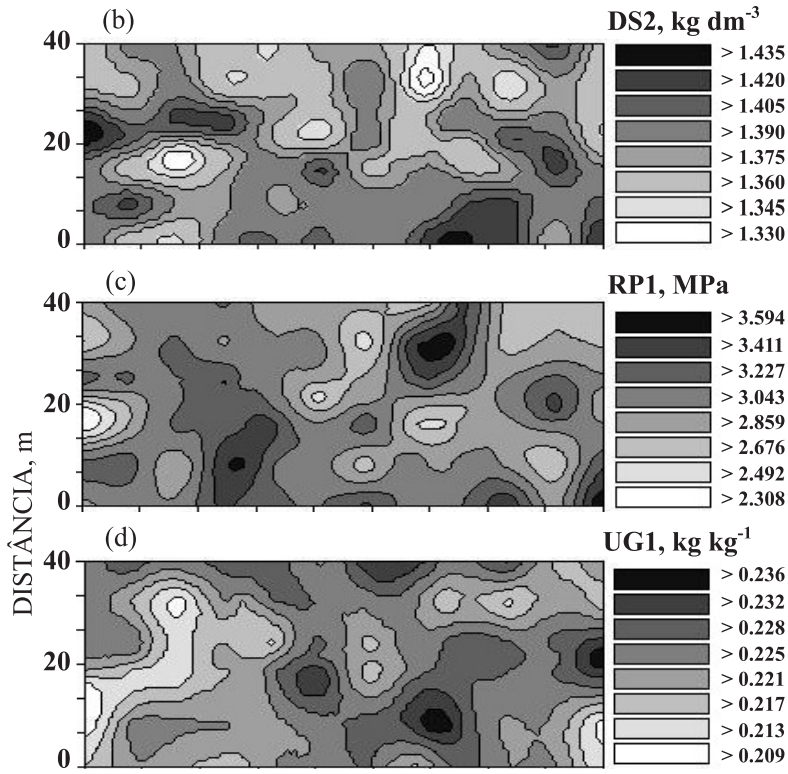

RP1, MPa

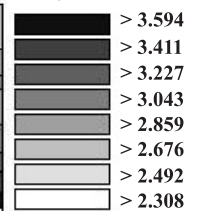

UG1, $\mathrm{kg} \mathrm{kg}^{-1}$

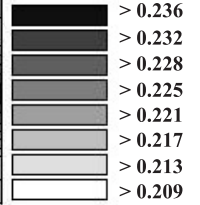

(e)

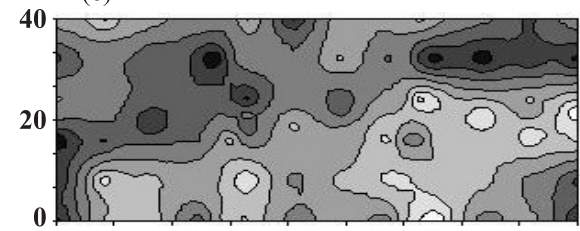

(f)

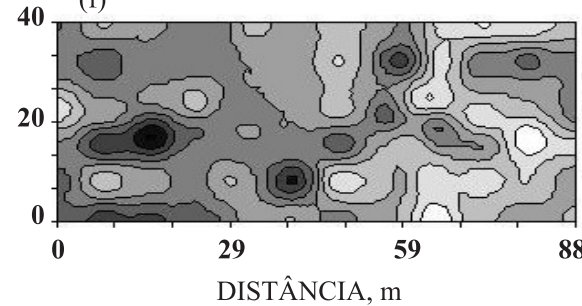

$\mathrm{UV} 1, \mathbf{m}^{3} \mathbf{m}^{-3}$
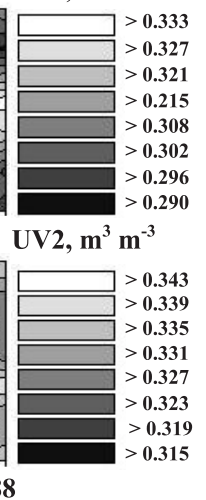

Figura 2. Mapas de krigagem simples da produtividade da soja e de alguns atributos físicos de um Latossolo Vermelho distroférrico de Selvíria (MS).

onde a UV2 foi menor, entre 0,315 e $0,327 \mathrm{~m}^{3} \mathrm{~m}^{-3}$ (travessão horizontal da cruz), a PG teve maiores valores $\left(3.318\right.$ e $\left.3.729 \mathrm{~kg} \mathrm{ha}^{-1}\right)$. Já naqueles onde a UV2 foi maior, entre 0,327 e $0,343 \mathrm{~m}^{3} \mathrm{~m}^{-3}$ (travessão vertical da cruz), a PG teve seus menores valores (2.770 e $3.318 \mathrm{~kg} \mathrm{ha}^{-1}$ ). Esse mesmo comportamento inverso entre tais variáveis (planta e solo) ficou plenamente de acordo com o observado por Gonçalves et al. (1998), Santos et al. (2005), Kitamura et al. (2007) e Lima et al. (2007). Assim, os dois primeiros trabalharam com a resistência à penetração e a produtividade de grãos de feijão (respectivamente num Nitossolo Vermelho eutrófico do Estado do Paraná e num Latossolo
Vermelho distroférrico do Estado de São Paulo); o terceiro, com a granulometria do solo e a produtividade de grãos de feijão, também num Latossolo Vermelho distroférrico paulista; e o quarto com a produtividade de massa seca do milho safrinha e a densidade do Latossolo Vermelho distrófico paulista. Em relação ao restante dos atributos do solo (DS2, RP1, UG1 e o UV1), não foi notada, em nenhum isoladamente, a mesma semelhança que a UV2 proporcionou com a PG.

A melhor co-krigagem foi entre a PG e UV2 (Figura 3c,d), indicando que 67,4\% da variabilidade espacial da PG foram explicados pela variabilidade espacial da UV2. Também neste caso, pode-se, a partir dos dados da UV2, localizar as zonas de manejo para a cultura da soja que foi estabelecida na área
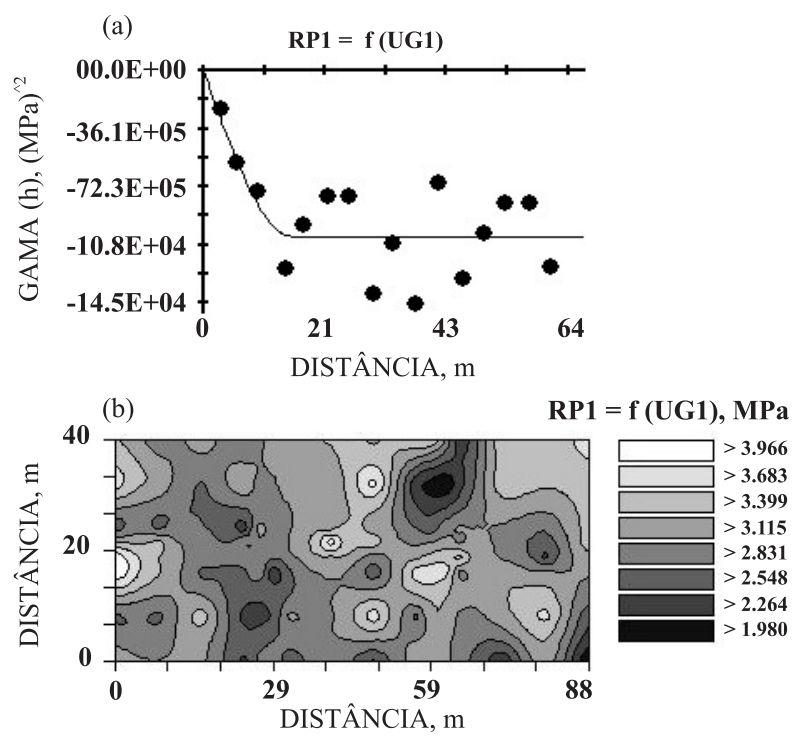

(c)
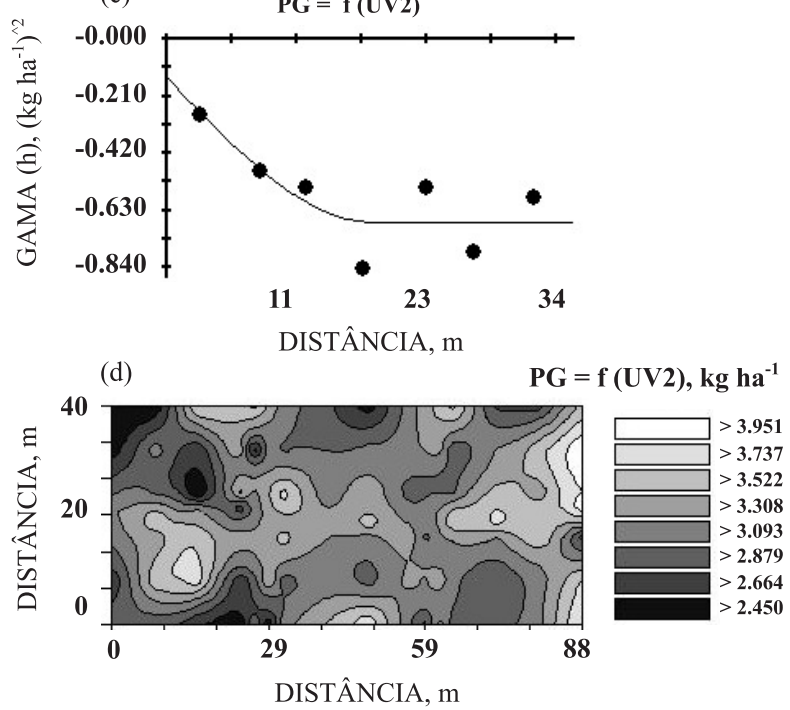

Figura 3: Semivariograma cruzado e mapas de cokrigagem da produtividade da soja e de alguns atributos físicos de um Latossolo Vermelho distroférrico de Selvíria (MS). 
experimental pesquisada. Assim, pôde-se constatar que onde ocorreram os menores valores de UV2 (Figura 2f) foram mapeados os maiores valores da PG (Figuras 2a e 3d). Em contrapartida, nos maiores valores da UV2 observaram-se os menores valores da PG. Sendo assim, podem ser recomendadas práticas conservacionistas às zonas de manejo, nas quais a UV2 teve seus maiores valores, visando-se elevar a respectiva produtividade de grãos de soja local. Do ponto de vista espacial, a umidade volumétrica, avaliada na camada de 0,10-0,20 m (UV2) apresentouse como um bom indicador da qualidade física do solo estudado, quando destinada à produtividade de grãos de soja.

\section{CONCLUSÕES}

1. A variabilidade dos valores da maioria dos atributos físicos do solo foi baixa, indicando que o plantio direto, possivelmente é um sistema que favorece a homogeneização do ambiente.

2. A produtividade de grãos de soja foi explicada por um modelo matemático linear inverso, em função da densidade do solo, quando obtida na camada de 0,10-0,20 $\mathrm{m}$ de profundidade do solo. Outrossim, os atributos pesquisados, que no geral não variaram aleatoriamente, seguiram padrões espaciais bem definidos, com alcances da dependência espacial entre 7,1 e 19,7 m. Portanto, do ponto de vista espacial, a produtividade de grãos de soja pode ser estimada por meio da umidade volumétrica, quando obtida na camada de 0,10-0,20 m de profundidade do solo.

3. A densidade do solo apresentou-se como potencial indicador da produtividade de grãos de soja.

\section{AGRADECIMENTO}

À Fundação de Amparo à Pesquisa do Estado de São Paulo (FAPESP), pela concessão da bolsa de estudos ao primeiro autor e pelo auxílio financeiro ao desenvolvimento do projeto.

\section{LITERATURA CITADA}

ARSHAD, M.A.; LOWERY, B. \& GROSSMAN, B. Physical tests for monitoring soil quality. In: DORAN, J.W. \& JONES,A., eds. Methods for assessing soil quality. Madison, Soil Science Society of America, 1996. p. 123141 (SSSA Special Publication, 49)

BENGOUGH, A.G.; CAMPBELL, D.J. \& O' SULLIVAN, M.F. Penetrometer techniques in relation to soil compaction and root growth. In: SMITH, K.A. \& MULLINS, C.E. Soil and environmental analysis: Physical methods. 2.ed. Edinburgh, Marcel Dekker, 2001. p.377-403.
BEUTLER, A.N.; CENTURION, J.F.; CENTURION, M.A.P.C. \& SILVA, A.P. Efeito da compactação na produtividade de cultivares de soja em Latossolo Vermelho. R. Bras. Ci. Solo, 30:787-794, 2006.

BEUTLER, A.N.; CENTURION, J.F.; CENTURION, M.A.P.C.; LEONEL, C.L.; CÁSSIA, A.G.S.J. \& FREDDI, O.S. Intervalo hídrico ótimo no monitoramento da compactação de um Latossolo Vermelho cultivado com soja em. R. Bras. Ci. Solo, 31:1232-794, 2007.

CARVALHO, M.P.; SORATTO, R.P. \& FREDDI, O.S Variabilidade espacial de atributos físicos em um Latossolo Vermelho distrófico sob preparo convencional em Selvíria, estado de Mato Grosso do Sul. Acta Sci. Agron., 24:13531361, 2002.

CARVAlho, G.J.; CARVAlHO, M.P.; FREDDI, O.S. \& MARTINS, M.V. Correlação da produtividade do feijão com a resistência à penetração do solo sob plantio direto. R. Bras. Eng. Agric. Amb., 10:765-771, 2006.

EMPRESA BRASILEIRA DE PESQUISA AGROPECUÁRIA EMBRAPA. Centro Nacional de Pesquisa de Solos. Manual de métodos de análise do solo. 2.ed. Rio de Janeiro, 1997.

EMPRESA BRASILEIRA DE PESQUISA AGROPECUÁRIA EMBRAPA. Centro Nacional de Pesquisa de Solos. Sistema brasileiro de classificação de solos. 2.ed. Rio de Janeiro, 2006. 306p.

EMPRESA BRASILEIRA DE PESQUISA AGROPECUÁRIA EMBRAPA SOJA. Disponível em: <http:// www.cnpso.embrapa.br.> Acesso em: 02 abr. 2008.

FAHL, J.I.; CAMARGO, M.B.P.; PIZZINATO, M.A.; BETTI, J.A.; MELO, A.M.T.; De MARIA, I.C. \& CANGIANI, A.M., eds. Instruções agrícolas para as principais culturas econômicas.. 6.ed. Campinas, Instituto Agronômico de Campinas, 1998. 396p. (Boletim, 200)

FREDDI, O.S.; CARVALHO, M.P.; VERONESI JÚNIOR, V. \& CARVALHO, G.J. Produtividade do milho relacionada com a resistência mecânica à penetração do solo sob preparo convencional. Eng. Agríc., 26:113-121, 2006.

GONÇALVES, A.C.A.; MATA, J.P.V.; VIEIRA, S.R. \& FOLEGATTI, M.V. Variabilidade espacial de produtividade e de resistência à penetração em área irrigada sob dois sistema de preparo. In: AVANCES EN EL MANEJO DEL SUELOS Y AGUA EM LA INGENIERÍA RURAL LATINOAMERICANA, La Plata, 1998. Anais. La Plata, UNLP, 1998. p.113-119.

GS+: Geostatistics for environmental sciences. 7.ed. Plainwell, Gamma Desing Software, 2004. 159p.

IMHOFF, S.; SILVA, A.P. \& TORMENA, C.A. Aplicação da curva de resistência no controle da qualidade física de um solo sob pastagem. Pesq. Agropec. Bras., 37:1493-1500, 2000 .

JOHANN, J.A.; URIBE-OPAZO, M.A.; SOUZA, E.G. \& ROCHA, J.V. Variabilidade espacial dos atributos físicos do solo e da produtividade em um Latossolo Bruno Distrófico da região de Cascavel, PR. R. Bras. Eng. Agric. Amb., 8:212-219, 2004. 
KIEHL, E.J. Manual de edafologia: Relações solo-planta. Piracicaba, Agronômica Ceres, 1979. 264p.

KITAMURA, A.E.; CARVALHO, M.P. \& LIMA, C.G.R. Relação entre a variabilidade espacial das frações granulométricas do solo e a produtividade do feijoeiro sob plantio direto. $\mathrm{R}$. Bras. Ci. Solo, 31:361-379, 2007.

LIMA, C.G.R; CARVALHO, M.P.; MELLO, L.M.M. \& LIMA, R.C. Correlação linear e espacial entre a produtividade de forragem, a porosidade total e densidade do solo de Pereira Barreto (SP). R. Bras. Ci. Solo, 31:1244, 2007.

MARINS, A.C. Métodos de estimação da função semivariância aplicados a dados simulados e reais de produtividade da soja e de atributos físicos de um Latossolo. Cascavel, Universidade Estadual do Oeste do Paraná. 2006. 140p. (Tese de Mestrado)

MERCANTE, E.; URIBE-OPAZO, M.A. \& SOUZA, E.G. Variabilidade espacial e temporal da resistência mecânica do solo à penetração em áreas com e sem manejo químico localizado. R. Bras. Ci. Solo, 27:1149-1159, 2003.

MESQUITA, M.G.B.F.; MORAES, S.O. \& CORRENTE, J.E. Caracterização estatística de variáveis físicas do solo. Acta Sci. Agron., 25:35-44, 2003.

OLIVEIRA, J.B. \& MONIZ, A.C. Levantamento pedológico detalhado da estação experimental de Ribeirão Preto, SP. Bragantia, 34:59-114, 1975.

SANTOS, P.A.; CARVALHO, M.P.; FREDDI, O.S.; KITAMURA, A.E.; FREITAS, E.E. \& VANZELA, L.S. Correlação linear e espacial entre o rendimento de grãos do feijoeiro e a resistência mecânica à penetração em um Latossolo Vermelho distroférrico. R. Bras. Ci. Solo, 29:287-295, 2005 .
SANTOS, M.L.; CARVALHO, M.P.; RAPASSI, R.M.A.; MURAISHI, C.T.; MALLER, A. \& MATOS, F.A Correlação linear e espacial entre produtividade de milho (Zea mays L.) e atributos físicos de um Latossolo Vermelho distroférrico sob plantio direto do Cerrado Brasileiro. Acta Sci. Agron., 28:313-321, 2006.

SECCO, D.; REINERT, D.J.; REICHERT, J.M. \& ROS, C.O. Produtividade de soja e propriedades físicas de um Latossolo submetido a sistemas de manejo e compactação. R. Bras. Ci. Solo, 28:797-804, 2004.

SECCO, D.; DA ROS, C.O.; SECCO, J.K. \& FIORIN, J.E. Atributos físicos e produtividade de culturas em um Latossolo Vermelho argiloso sob diferentes sistemas de manejo. R. Bras. Ci. Solo, 29:407-414, 2005.

SCHLOTZHAVER, S. D. \& LITTELL, R. C. SAS System for elementary statistical analysis. 2.ed. Cary, 1997. 905p.

SHAPIRO, S.S. \& WILK, M.B. An analysis of variance test for normality: Complete samples. Biometrika, 52:591-611, 1965.

SOUZA, Z.M.; SILVA, M.L.S.; GUIMARÃES, G.L.; CAMPOS, D.T.S.; CARVALHO, M.P. \& PEREIRA, G.T. Variabilidade espacial de atributos físicos em um Latossolo Vermelho distrófico sob semeadura direta em Selvíria (MS). R. Bras. Ci. Solo, 25:699-707, 2001.

SOUZA, Z.M.; CAMPOS, M.C.C.; CALVACANTE, I.H.L.; MARQUES JÚNIOR, J.; CESARIN, L.G. \& SOUZA, S.R. Dependência espacial da resistência do solo à penetração e do teor de água do solo sob cultivo contínuo de cana-deaçúcar. Ci. Rural, 36:128-134, 2006.

SPIEGEL, M.R. Estatística. 2.ed. São Paulo, McGraw-Hill do Brasil, 1985.

TRANGMAR, B.B.; YOST, R.S. \& UEHARA, G. Application of geostatistics to spatial studies of soil properties. Adv. Agron., 38:45-94, 1985. 
